\title{
CONTROLE DE INFECÇÃO HOSPITALAR: Conhecimento Adquirido na Graduação de Enfermagem
}

\author{
Hospital infection control: \\ Knowledge acquired at Nursing College.
}

Ana Paula Santos ${ }^{1}$

Clarice Mayremi Toshimitu Hoyashi ${ }^{2}$ Denise Celeste Godoy de Andrade Rodrigues ${ }^{3}$

\section{Resumo}

O estudo trata do discurso de acadêmicos de enfermagem sobre a atuação do enfermeiro no controle de infecção hospitalar. Tem como objetivos descrever o conhecimento de acadêmicos acerca do controle de infecção hospitalar e apontar estratégias de atuação destes no controle de infecção hospitalar para práticas futuras. O método utilizado é descritivo, de abordagem qualitativa. Os sujeitos foram 40 acadêmicos de enfermagem de uma universidade privada, localizada no município de Volta Redonda /RJ. O instrumento de coleta de dados foi um questionário com perguntas abertas. O período do estudo compreende os meses de julho e agosto de 2009. Os resultados mostraram que acadêmicos de enfermagem estão preparados para atuarem no controle de infecção hospitalar, como futuros profissionais de saúde. Possuem bom entendimento sobre a atuação do enfermeiro, onde privilegiam importantes papéis como a implementação da educação continuada, procedimentos técnicos essenciais ao controle de infecçóes e o gerenciamento das açôes. Bem como, utilização de estratégias que visem a prevenção ou controle, como a capacitação da equipe de enfermagem em, como por exemplo a lavagem das mãos, método simples, mas de grande eficácia para evitar agravos de doenças.

Palavras-chave: Atuação do Enfermeiro; Controle de Infecção hospitalar; Cuidados de Enfermagem.

\section{Abstract}

This study presents the nursing students discourse about the nurse action in the hospital infection control. It aims to describe the academic knowledge about the hospital infection control and points out strategies of action against the hospital infection to future practices. It was used a qualitative approach. The subjects were 40 nursing academics in a private college located in Volta Redonda, Rio de Janeiro state. An open questionnaire was used as data gathering. This study occurred during July and August 2009. The results show that the nursing academics are prepared to act in the hospital infection control as future health professionals. They have a good understanding of the nurse action, which emphasizes important roles such as the implementation of continuous education, essential technical procedures to the infection control and the action management. As well as the use of strategies such as the training of the nursing staff in simple methods but very useful to avoid the diseases increase, for example washing hands.

Keywords: Nurses Actuation, Hospital Infection Control, Nursing.

${ }^{1}$ Graduanda do Curso de Enfermagem do Centro Universitário de Volta Redonda - UniFOA. ${ }^{2}$ Aluna regular do Mestrado em Ensino em Ciências da Saúde e do Meio Ambiente - Mestrado Profissional- UniFOA, Docente e Orientadora do Curso de Enfermagem do Centro Universitário de Volta Redonda - UniFOA.

${ }^{3}$ Docente do Mestrado em Ensino em Ciências da Saúde e do Meio Ambiente - Mestrado Profissional- UniFOA; Docente do Programa de Pós-Graduação em Química da UERJ. 


\section{INTRODUÇÁO}

O enfermeiro é um profissional capacitado a exercer suas funçôes com base em conhecimentos científicos aplicados à prática. Com essa premissa, a construção desse conhecimento se inicia durante a formação acadêmica.

A base de todo o conhecimento adquirido na graduaçáo em enfermagem é fundamentada em ações de promoção, recuperação ou restabelecimento da saúde do indivíduo. Nesse sentido, a temática desse estudo foi voltada para a atuação de futuros enfermeiros no controle de infecção hospitalar.

A educação náo só deve adequar-se ao mundo em que se verifica, como tambémé fator de progresso desse mundo. (...) O processo educativo tem dois aspectos: um psicológico, que consiste na exteriorização das potencialidades do indivíduo, e outro social, que consiste em preparar o indíviduo para as tarefas que desempenhará na sociedade. Cabe a escola tentar harmonizar os dois aspectos, tendo em vista que as potencialidades do aluno só encontram significado dentro de um ambiente social.(PILETTI e PILETTI, 2008)

Comportamento e atitudes são derivados da formação educacional do indivíduo, o ensino-aprendizagem é o reflexo da postura e competência profissional.

Em análise, num ensino inovador, a construção desses conhecimentos está pautada em experiências vivenciadas da realidade docente e discente, em uma troca constante de teorias e práticas.

O conhecimento consiste em representaçôes da realidade, construídas no decorrer das experiências vividas e no processo de formaçáa. Já as competências são capacidades para utilizar esses conhecimentos, integrá-los ou mobilizálos, visando à resolução dos diversos problemas enfrentados no cotidiano. (TEIXEIRA et al., 2006)

Assim pode-se ainda enfatizar que, um ensino de qualidade, possibilita fazer uma análise da aprendizagem dos discentes, avaliando o exercício do pensamento e atitudes que precedem a prática profissional. Nesse sentido, busca-se estudar o entendimento de acadêmicos de enfermagem em situações específicas à futura prática profissional.

O estudo trata do discurso de acadêmicos de enfermagem sobre a atuação do enfermeiro no controle de infecção hospitalar.

O interesse em realizar esse estudo se deu pelo fato de ser acadêmica de enfermagem e durante o estágio supervisionado num hospital geral, foi observado a ocorrência de infecção hospitalar nos pacientes sob atendimento da enfermagem.
Pela visão acadêmica e a construção do conhecimento científico, despertou-se o interesse em dissertar sobre a temática.

É relevante aos acadêmicos de enfermagem a obtenção de conhecimentos que possam promover medidas de controle de infecção hospitalar, podendo beneficiar diretamente os pacientes que estấo sob seus cuidados.

$\mathrm{O}$ atendimento à pacientes num hospital, requer atençấo e cuidados de enfermagem especiais. $\mathrm{O}$ fato de pacientes serem submetidos à vários procedimentos na área hospitalar, seja em pronto socorro ou em unidades de internação, torna os indivíduos suscetíveis a adquirirem infecção hospitalar.

A evoluçáo tecnológica na área da saúde trouxe aumento nas oportunidades de êxito aos procedimentos diagnósticos e terapêuticos e, consequentemente, aumento das expectativas de cura e reabilitaçâo das enfermidades. Entretanto, essa evoluçáo tem sido cada vez mais desafiadora ao controle de infecção relacionada à assistência à saúde. (POSSARI, 2008)

De acordo com Lima (2007) infecção hospitalar é aquela adquirida após a admissão do paciente, que se manifesta durante a internação ou após a alta, e pode ser relacionada com a internação ou procedimento hospitalares.

A suscetibilidade do paciente a infecção durante a internação tende a ser aumentado devido ao constante contato com pacientes de diversas patologias em ambiente fechado, o uso de materiais em procedimentos médicos e de enfermagem, o contato com os profissionais de saúde e a própria vulnerabilidade do indivíduo a determinadas exposições à doenças, predispõe à infecções secundárias que se relacionam com a hospitalização.

Desta forma, é importante traçar um paralelo entre os procedimentos de enfermagem e a possibilidade da ocorrência da infecção hospitalar, para tanto é fundamental levar em consideração: o ambiente hospitalar, a microbiota humana, a resistência de cada indivíduo ao ataque microbiano e os procedimentos invasivos ou não invasivos. (SILVA, PEREIRA e MESQUITA, 2004)

Os pacientes hospitalizados recebem cuidados de enfermagem ao longo da internaçâo, sendo assim, cabe a essa equipe a prevenção e o controle das infecçôes hospitalares. É papel do enfermeiro atuar neste controle, implementando estratégias de treinamento das açôes de enfermagem dando enfoque ao risco potencial de infecção, adotando medidas que possam minimizar as complicaçóes, atentando para execução de procedimentos de enfermagem. 
A manifestação da infecção hospitalar pode ocorrer após a alta, desde que esteja relacionada com algum procedimento realizado durante a internação. Somente um profissional treinado (médico ou enfermeiro com qualificação especial em Infecçâo Hospitalar) pode relacionar sinais e sintomas de infecçấo com procedimentos realizados em unidades de saúde e realizar o diagnóstico de infecção hospitalar.(RODRIGUES et al, 2008)

O estudo poderia abordar o histórico da infecção hospitalar, questóes éticas ligadas ao controle da infecção hospitalar, no entanto nesse momento, optou-se por estudar somente o entendimento de acadêmicos de enfermagem sobre a atuação do enfermeiro no controle de infecção hospitalar.

As questóes que nortearam esse estudo, basearam-se nas perguntas:

- Qual o entendimento de acadêmicos de enfermagem acerca do conhecimento adquirido sobre a atuação do enfermeiro no controle de infecção hospitalar?

- Que estratégias poderão ser adotadas por acadêmicos de enfermagem no controle da infecção hospitalar para práticas futuras?

Diante do exposto, os objetivos traçados para o estudo foram as seguintes:

- Descrever o entendimento de acadêmicos de enfermagem acerca da atuação do enfermeiro no controle de infecção hospitalar.

- Apontar estratégias de atuação de acadêmicos de enfermagem no controle de infecção hospitalar para práticas futuras.

O estudo poderá contribuir para o ensino e também para a prática na enfermagem. No ensino, a intenção é tentar a conscientizaçáo de acadêmicos sobre o importante papel do enfermeiro no controle de infecçóes hospitalares, onde busca-se multiplicar açóes de enfermagem utilizando medidas que possam reduzir a incidência de infecção hospitalar, em futuras atuaçóes. Na prática, poderá influenciar positivamente em mudanças que valorizem a atuação da enfermagem nos métodos que visem reduzir ou controlar infecçôes hospitalares. O estudo também poderá contribuir para a pesquisa, a divulgação desse trabalho poderá motivar a comunidade científica nas investigaçóes literárias.

Emerge então, a seguinte questão problema:

- Será que acadêmicos de enfermagem estáo preparados para atuar no controle das infecçóes hospitalares?

\section{REVISÃO BIBLIOGRÁFICA}

\section{1 - Atuaçáo do Enfermeiro na Prevenção e Controle de Infecçáo Hospitalar}

Compete ao enfermeiro dentro de suas atribuiçóes supervisionar, organizar, planejar e executar medidas que possam favorecer a prevençáo de infecçóes decorrentes da hospitalização. Deve envolver toda a sua equipe de trabalho, incluindo a participação da equipe interdisciplinar de saúde.

Assim, podemos destacar algumas de suas atribuiçóes nesse processo: fazer rotineiramente uma visita ao hospital para detectar algum problema; elaborar plano de limpeza, desinfecção e esterilização das unidades; em conjunto com os demais profissionais da Comissão de Controle de Infecção Hospitalar (CCIH), normalizar a utilização de germicidas hospitalares; avaliar e orientar medidas de isolamento e precauçóes de doenças perante a equipe multiprofissional [....]. (MINAYO, 2008)

Ao levantar as várias possibilidades de contaminação e riscos de infecção nos pacientes, o enfermeiro pode classificar por áreas, sua atuação no ambiente hospitalar, citamos algumas ações preventivas nesse controle.

Quanto ao ambiente hospitalar, os recipientes de coleta de roupa suja devem possuir tampas acionadas por pedal e devem ser mantidas continuamente fechadas [...]. Quanto aos profissionais, sempre trocar as luvas e lavar as mãos entre a execução dos procedimentos, mesmo que em um mesmo paciente,[...]. Quanto ao preparo de infusôes, náo esquecer de utilizar as barreiras de proteção (equipamentos de proteção individual); quanto ao descarte dos resíduos dos serviços de saúde, não reencapar agulhas e utilizar as caixas coletores de perfurocortantes até o limite máximo de $2 / 3$ de sua capacidade total, evitando acidentes. (SILVA, PEREIRA e MESQUITA, 2004)

A prevenção e controle de infecção hospitalar merecem cada vez mais atenção dos serviços de saúde, pois, tendo o enfermeiro a frente às estratégias, implementação de açôes em parceria com a equipe interdisciplinar, poderá viabilizar resultados satisfatórios referentes aos índices de infecção hospitalar. 


\section{2 - Cuidados de Enfermagem e a Prevenção de Infec- ção Hospitalar}

A equipe de enfermagem permanece 24 horas ao lado do paciente hospitalizado, observando e implementando cuidados de enfermagem prescritos por enfermeiros ou atendendo as prescriçóes médicas. Para que a assistência prestada seja adequada enfocando a prevençáo ou evitando complicaçôes de doenças, faz-se necessário uma vigilância permanente e o cumprimento de rotinas e protocolos institucionais, tecnicamente direcionados pela Comissão de Controle de Infecção Hospitalar (CCIH).

O cuidado de enfermagem enfoca a vigilância da infecção hospitalar como consequência da infecção de pacientes em estado de saúde grave, mas a questão técnica foi respaldada pelos protocolos instituídos e acompanhados pela Comissão de Controle de Infecção Hospitalar desse hospital. (LIMA, 2007)

Embora seja enfática e necessária, a atuação da enfermagem em prol da recuperação de pacientes hospitalizados, que visa a promoção de retorno às atividades do cotidiano, também é sua responsabilidade o autocuidado durante a implementação de cuidados nesses pacientes, isto é, prevenir possíveis acidentes de trabalho durante a sua atuação, evitando contrair doenças durante o exercício profissional.

Para Carvalho e Bianchi (2007), todas as profissôes envolvem riscos inerentes à natureza de sua própria especialidade e ao ambiente onde o profissional atua, podendo ser responsáveis por acidentes de trabalho ou doenças profissionais.

A vulnerabilidade da equipe de enfermagem em adquirir doenças na interação paciente-enfermagem é bastante preocupante, portanto, os cuidados de enfermagem devem ser planejados e executados de forma que proteja o paciente, evitando complicaçóes da doença, assim como diminuir os riscos ocupacionais a essa equipe.

\section{METODOLOGIA}

Secaf (2007) disse que escrever um trabalho científico é uma tomada de decisão que envolve o crescimento do profissional e melhores oportunidades na carreira.

A pesquisa científica requer a busca de várias literaturas que possam embasar e solidificar o estudo proposto dentro da área de conhecimento de cada pesquisador.

O método de pesquisa escolhido foi o descritivo exploratório e de caráter qualitativo.

A pesquisa qualitativa é caracterizada por possibilitar compreender fenômenos e investigar dados subjetivos, per- mitindo-nos interpretar os dados colhidos.

"Está direcionada para a investigação dos significados das relaçôes humanas, onde suas açôes são influenciadas pelas emoções e/ ou sentimentos aflorados diante das situaçôes vivenciadas no dia- a - dia”. (FIGUEIREDO, 2009)

A descrição, o registro das informaçóes colhidas caracteriza a legitimidade do estudo.

As pesquisas descritivas têm como objetivo principal a descrição das características de determinada população ou fenômeno ou entáo o estabelecimento de relações entre variáveis e obtidas através da utilização de técnicas padronizadas de coleta de dados, como o questionário e a observação sistemática. (SEVERINO, 2005)

A pesquisa descritiva usa a descrição de pessoas ou intuiçôes de relação entre variáveis obtidas através de questionário e coleta de dados, ampliando o conteúdo da temática.

"A pesquisa exploratória busca apenas levantar informaçôes sobre determinado objeto, delimitando assim um campo de trabalho, mapeando as condições de manifestação desse objeto". (SEVERINO, 2005). Este estudo possibilita a análise de fenômenos e a busca de novas idéias, encontrando um viés para explicar o entendimento de acadêmicos de enfermagem sobre o controle de infecção hospitalar.

Os sujeitos da pesquisa foram quarenta acadêmicos de enfermagem do $8^{\circ}$ período do Centro Universitário de Volta Redonda (UniFOA), instituição de ensino superior particular localizada no município de Volta Redonda (RJ). O $8^{\circ}$ período foi escolhido, por ser o último período da graduação de enfermagem, tendo em vista que esses alunos já tiveram todo o conteúdo teórico sobre essa temática e estão atualmente no exercício da prática no campo de estágio. A pesquisa ocorreu entre os meses de julho e agosto de 2009.

O instrumento utilizado para a coleta de dados foi um questionário com duas perguntas abertas:

1- Qual a atuação do enfermeiro no controle de infecção hospitalar? Descreva.

2 - Que estratégias poderiam ser adotadas no controle da infecção hospitalar, em práticas futuras? Descreva.

"O questionário é a forma mais usada para coleta de dados, pois possibilita medir com mais exatidáo o que se deseja”. (CERVO, BERVIAN e SILVA, 2007)

Durante toda a pesquisa e coleta de dados, as informaçóes colhidas foram mantidas em sigilo e sendo garantidos os anonimatos dos informantes. O estudo foi aprovado pelo Comitê de Ética em Pesquisa com Seres Humanos (CoPES) do UniFOA. Os sujeitos concordaram em participar da pesquisa, assinando o Termo de Consentimento Livre e Esclarecido, 
conforme resolução 196/96 da Pesquisa com Seres Humanos.

Após a coleta de dados com o objetivo de fundamentar o estudo, realizou-se a análise dos depoimentos dos acadêmicos de enfermagem e a organização dos resultados dos questionários de forma que pudesse ser clara e objetiva para a argumentação baseada em evidências.

Com relação a análise dos dados, primeiramente, todos os questionários foram numerados, na intenção de manter o sigilo das informaçóes, independente da identificação nominal dos depoentes, optando por identificar cada questionário numericamente de 1 a 40. Depois, cada resposta foi analisada individualmente e ao mesmo tempo sendo agrupadas por descriçóes similares. Os agrupamentos de respostas originadas de cada pergunta formaram as categorias.

\section{ANÁLISE E INTERPRETAÇÃO DOS DADOS}

O questionário aplicado aos sujeitos do estudo fundamentou com dados significativos o desenvolvimento da pesquisa, a interpretação das respostas evidenciou fatos verdadeiros e legítimos. Com relação às perguntas do questionário, a primeira foi relacionada sobre a atuação do enfermeiro no controle de infecção, onde emergiram três categorias de respostas: educação continuada, procedimentos técnicos e gerenciamento.

\section{Educaçáo continuada}

Identificou-se neste estudo que 20 (50\%) dos acadêmicos de enfermagem que referiram a educação continuada como um dos principais papéis do enfermeiro no controle de Infecção Hospitalar, conforme relatos abaixo:

"É responsabilidade do enfermeiro realizar o treinamento da equipe para que as práticas exercidas sejam feitas de forma asséptica. Realizar a educação continuada, facilita a compreensáo da equipe quanto as medidas de controle da infecção hospitalar e sua importância.” Dep. 34.

"Realizar açôes preventivas, educação continuada junto a sua equipe." Dep. 31.

"O enfermeiro atua educando sua equipe e os demais profissionais no âmbito hospitalar.” Dep. 01.

Com base na análise das respostas, foi interessante a abordagem dos depoentes sobre a educação continuada, porque rotinas e protocolos institucionais implantados pela Comissão de Controle de Infecções Hospitalar (CCIH) só terão efeitos satisfatórios com o envolvimento de toda a equipe interdisciplinar de saúde.
O enfermeiro deve ter, em seu quadro de pessoal, profissionais com capacidade de receber treinamento, tendo em vista o estudo de redução de tempo e de movimentos necessários no setor, contribuindo para uma ampliação da quantidade de açôes desenvolvidas, bem como para melhorar a qualidade dessas açôes. (MOURA, 2009)

A educação permanente se faz necessária no ambiente hospitalar, deve se exigir do enfermeiro uma visão global para abranger suas necessidades e de sua equipe, buscando sempre embasamento cientifico para realização de técnicas mais complexas à mais simples.

Educação e Enfermagem, juntas, tornam-se tarefas árduas maiores que a soma das duas áreas. Mas o educador sabe, e o Enfermeiro também que, quando bem sucedidos, os resultados de uma intervençáo educativa e de enfermagem promovem grande satisfação.(MALAGUTTI e BONFIM, 2008).

Vemos então que cabe aos enfermeiros, reconhecer a importância de procurar formas de articulação entre diferentes áreas do conhecimento, o diálogo com os seus parceiros de trabalho, decide reorientar a prática das açôes educativas da equipe de interdisciplinar nas instituiçóes de saúde.

"Nos processos educativos, considera-se essencial o sujeito que aprende o objeto a ser aprendido, o conhecimento resultante da interaçáo entre o sujeito e o objeto e o instrutor, como facilitador desse processo". (SERVO e CORREIA, 2006)

\section{Procedimentos técnicos}

Observou-se que nessa categoria, 10 (25\%) dos depoentes entenderam que a atuação do enfermeiro no controle de infecção hospitalar está fundamentada na utilização de técnicas preconizadas, onde se respeita os princípios científicos que possam minimizar a incidência de infecção adquirida conforme alguns relatos abaixo.

\footnotetext{
"Atentar para a lavagem das mãos, a realização de procedi-
} mentos adequadamente entre outras açóes.” Dep.04.

"Evitar sempre a infecção através da lavagem das mãos, realização das técnicas de forma adequada." Dep.28.

"Todas as ações em que o enfermeiro está realizando procedimentos, ele é responsável em manter certas açōes para prevenir a infecção hospitalar, como lavar as máos entre lidar com o paciente e outro.” Dep.32. 
Para alguns dos depoentes, como citado no texto, a utilização da precaução padrão é a mola mestra na prevenção e controle de infecção hospitalar, assim como todas as outras técnicas fundamentadas cientificamente para facilitar o procedimento e reduzir os riscos para pacientes e profissionais de saúde.

Pelas mãos podemos transmitir, a nós mesmos e aos outros, infecções muito sérias. De todas as recomendações, a de lavar as mãos talvez seja a menos seguida. É possível que sejamos tão resistentes em lavar as mãos porque vírus, fungos e bactérias são seres tão minúsculos que, no fundo, não acreditamos na existência deles. No entanto, é difícil manter essa idéia depois de três centenários da existência do microscópio.(SANTOS e VIANA, 2009)

A conscientização da higienização das mãos e a execução plena conforme as indicaçóes preconizadas pela literatura podem contornar o problema da infecção hospitalar. A prática de lavar as mãos deve ser considerada como hábito, antes e depois da execução de qualquer procedimento de enfermagem.

A higienização das mãos é reconhecida, mundialmente, como uma medida primária, mas muito importante no controle de infecçôes relacionadas à assistência à saúde. Por este motivo, tem sido considerada como um dos pilares da prevençấo e controle de infecçóes dentro dos serviços de saúde, incluindo aquelas decorrentes da transmissão cruzada de microrganismos multirresistentes. (ANVISA, 2009)

A prevenção e o controle das infecções relacionadas à assistência à saúde é um grande desafio para a enfermagem. Uma medida simples, a higienização apropriada das mãos, é considerada a mais importante e eficaz para reduzir a transmissão de infecçôes em serviços de saúde.

\section{Gerenciamento}

Os depoentes, 10 (25\%) identificaram o gerenciamento como principal atuação do enfermeiro na prevenção e controle de infecção hospitalar. A orientação, organização, planejamento e supervisão são maneiras de controlar as atividades desenvolvidas sob sua responsabilidade, que podem diretamente, produzir um impacto no tratamento do paciente, como se observa nos depoimentos:

"Elaboração de protocolos sobre prevenção de infecção hospitalar, supervisão a fim de observar a prática da equipe." Dep.09.
"Inspecionar os setores hospitalares observando as técnicas, a limpeza e a organização a fim de diminuir o índice de infecção hospitalar. Promovendo também reuniōes e educação permanente para conscientização dos profissionais." Dep.30.

"Atua nas orientaçóes da equipe multiprofissional, é responsável por demonstrar na prática como promover este controle." Dep.03.

Sabemos que a elaboração e implementação de rotinas de prevenção, diagnóstico e tratamento de infecção hospitalar é uma das atividades complexas, no entanto a mais importantes que exige a intervençáo do enfermeiro gerente.

Segundo Figueiredo et al (2009) é função do enfermeiro coordenar, controlar, orientar e avaliar todo o trabalho de sua equipe. (...) É ele o responsável pelo equilíbrio físico e mental da equipe, por meio de exercícios de práticas humanas de ajuda, de apoio emocional e de encaminhamento de problemas detectados. Também é responsável pelo sucesso ou fracasso do desempenho de sua equipe.

Para um gerenciamento de qualidade, é necessário uma nova abordagem gerencial, que permita profissionais acompanharem mudanças e até mesmo anteciparem a elas, pois enfatiza a melhoria contínua de produtos e serviços, pela utilização do método científico e monitorizarão de dados que embasam a tomada de decisóes.

Ao analisar a segunda pergunta do questionário, os depoentes apontaram estratégias de açóes que poderiam adotar no controle de infecção hospitalar em futura prática profissional, emergindo as seguintes categorias de respostas: capacitaçâo da equipe de enfermagem e lavagem das mãos.

\section{Capacitaçáo da equipe de enfermagem}

A capacitação da equipe de enfermagem foi a estratégia mais apontada pelos sujeitos da pesquisa. Dos 40 (100\%) dos depoentes, 30 (75\%) privilegiam essa ação, como a mais conveniente e essencial para o controle de infecção hospitalar. Dentre as falas dos depoentes se destacaram os seguintes:

\footnotetext{
"Maior nível de conhecimento sobre as fontes de infecção e as medidas para evitar a contaminação, orientar e educar a equipe. E trazer novas fontes de conhecimentos através de pesquisa e aprimoramento das informaçóes." Dep.32.
}

"Palestras e capacitação da equipe de enfermagem. Incentivar a equipe para a melhor realização das técnicas" Dep.07. 
"Realização de reuniôes periódicas com toda a equipe de enfermagem, onde o CCIH estaria passando todo o conhecimento e aceitando sugestóes dos profissionais." Dep.12.

O desafio da educação permanente é estimular o desenvolvimento da consciência nos profissionais sobre o seu contexto, pela sua responsabilidade em seu processo permanente de capacitação.

A relação do cuidado é uma interdependência baseada no dia-a-dia do profissional de enfermagem, "segundo a qual a ação do cuidar é interdependente e se constrói no cotidiano das atividades de enfermagem, na sua dimensão objetiva, na subjetividade de quem cuida e do ser cuidado e, através da mediação das interaçóes de espaço tempo, parte-se para pensar nessa construçáo nas suas dimensóes individual e coletiva. (SHINVASHIKI, TREVIZAN e MENDES, 2003)

É necessário rever os métodos utilizados nos serviços de saúde para que a educação permanente seja, para todos um processo sistematizado e participativo, tendo como cenário o próprio espaço de trabalho, no qual o pensar e o fazer são insumos fundamentais do aprender e do trabalhar.

\section{Lavagem das mãos}

A lavagem das mãos é um procedimento técnico multiprofissional que contribui de forma satisfatória no controle e prevenção de infecção hospitalar. Sua importância é tamanha, que não deixaria de ser citada por 10(25\%) dos depoentes com a estratégia de ação para o controle de infecção. E então, descreveram:

\begin{abstract}
"Lavagens das mãos, realização dos procedimentos de forma correta, realizar a assepsia dos materiais corretamente e junto a educaçáo continuada observar se a equipe esta manipulando as técnicas de forma correta." Dep.31.
\end{abstract}

“Conscientização para a lavagem das mãos.” Dep.19

"Lavar as mãos antes e após cada procedimento. Usar álcool gel. Utilizar material de proteção individual.” Dep.11.

Levando-se em consideração o fato de que a necessidade de higienização das mãos é reconhecida por diversas entidades, entre elas o Ministério da Saúde, inclui-se recomendações para esta prática.

\begin{abstract}
A Portaria do Ministério da Saúde MS nº. 2616, de 12 de maio de 1998 estabelece as ações mínimas a serem desenvolvidas sistematicamente, com vistas à redução da incidência e da gravidade das infecções relacionadas aos serviços de saúde. Destaca também a necessidade da higienização das mãos em serviços de saúde. (ANVISA, 2009)
\end{abstract}

Sabe-se que o ato de cuidar envolve a disciplina da própria higiene e do outro, podendo prevenir assim risco não só para o paciente como também para o profissional. Portanto, prevenção e controle de infecção hospitalar estão nas mãos dos profissionais de saúde que interagem com os clientes-pacientes e, ainda, cabendo-lhe a responsabilidade moral e técnica na execução de medidas que possam minimizar os riscos para o próprio trabalhador.

\section{CONCLUSÃO}

Atualmente, a infecção hospitalar têm sido um dos temas mais discutidos nas instituiçôes de saúde. $\mathrm{Na}$ área de enfermagem, a implementação de cuidados diretos ou indiretos, podem influenciar no desenvolvimento de complicaçóes, principalmente das infecçóes hospitalares. Os pacientes podem ser suscetíveis à infecção por microrganismos oportunistas, principalmente, quando se refere à hospitalização.

Entretanto, a enfermagem e equipe multidisciplinar também tornam-se vulneráveis e podem oportunizar a ocorrência de infecçôes durante a implementação de seus cuidados.

$\mathrm{O}$ enfermeiro atua com base em conhecimentos científicos a fim de promover e restabelecer a saúde dos pacientes. Contudo, a construção desse conhecimento se inicia enquanto acadêmico. A compreensão das necessidades e o perfil de sua atuação é traçado a partir da academia e a projeção desse aprendizado poderá ser comprovada em práticas profissionais.

Neste estudo, os resultados puderam mostrar que acadêmicos de enfermagem estáo preparados para atuarem no controle de infecção hospitalar, como futuros profissionais de saúde. Pode-se constatar nas respostas dos depoentes no que se refere ao seu entendimento sobre a atuação do enfermeiro, surgindo categorias: educação continuada, procedimentos técnicos e gerenciamento. Quanto às estratégias adotadas por acadêmicos em relação ao controle de infecção hospitalar em futuras práticas, emergiram essas categorias: capacitação da equipe de enfermagem e lavagem das mãos. A partir da análise das respostas, pode-se concluir entâo que, esses acadêmicos possuem bom entendimento sobre a atuação do enfermeiro, onde privilegiam importantes papéis. Bem como, utilização de estratégias que visem à prevenção ou controle de infecção hospitalar, utilizando métodos simples, porém efetivos e que possam trazer resultados satisfatórios na redução dos índices de infecção hospitalar. 


\section{REFERÊNCIAS}

ANVISA. Agência Nacional de Vigilância Sanitária. 21 nov. 2009. Disponível em URL: http://www.anvisa.gov.br/ servicosaude/manuais/paciente_hig_maos.pdf.

CARVALHO, R; BIANCHI, E.R.F.(orgs.). Enfermagem em Centro Cirúrgico e Recuperaçáo. Barueri, SP: Manole, 2007.

CERVO, A.L; BERVIAN, P.A; SILVA, R. Metodologia científica. 6 ed. São Paulo: Pearson Prentice, 2007.

FIGUEIREDO, N.M.A; LEITE, J.L; MACHADO, W.C.A. Centro Cirúrgico - atuaçáo, intervençáo e cuidados de enfermagem. 2a ed. rev. atual. São Caetano do Sul, SP: Yendis Editora, 2009.

FIGUEIREDO, N.M.A. Método e metodologia na pesquisa científica. 3 ed. São Caetano do Sul, SP: Yendis Editora, 2009.

LIMA, M.V.R. Condutas em controle de infecçáo hospitalar: uma abordagem simplificada. Sáo Paulo: Iátria, 2007.

MALAGUTTI, W; BONFIM, I.M. Enfermagem em Centro Cirúrgico - atualidades e perspectivas no ambiente cirúrgico. São Paulo: Martinari, 2008.

MINAYO, M.C.S. Pesquisa social: teoria, método e criatividade. In:__ Saberes e práticas: guia para ensino e aprendizado de enfermagem. 4 ed. São Paulo: Difusão, 2008. 1v.

MOURA, M.L.P..A. Enfermagem em Centro de Material e Esterilizaçáo. 9a ed. São Paulo: Editora Senac São Paulo, 2009.

PILETTI, C; PILETTI, N. Filosofia e História da Educaçáo. 15a ed. São Paulo: ABDR, 2008.

POSSARI, J.F. Centro Cirúrgico: Planejamento, Organização e Gestão. 3a ed. São Paulo: Iátria, 2008.

RODRIGUES, A.B; SILVA, M.R; OLIVEIRA, P.P; CHAGAS, S.S.M. O Guia da Enfermagem. $1^{\text {a }}$ ed. São Paulo: Iátria, 2008.

SANTOS, V.E.P; VIANA, D.L. Fundamentos e Práticas para Estágio em Enfermagem. $3^{\text {a }}$ ed. São Caetano do Sul, SP: Yendis Editora, 2009.

SECAF, V; Artigo Científico: do desafio à conquista Com enfoque em Teses e outros trabalhos acadêmicos. $4^{\mathrm{a}}$ ed. São Paulo: Martinari, 2007.
SERVO, M.L; CORREIA,V.S. Supervisão e a educaçáo permanente da força de trabalho em enfermagem. Rev. Eletrônica da Facul. de Tecnologia e Ciências. 8 de junho 2006. Disponível em: http://www.ftc.br/revistafsa.

SEVERINO, A.J. Metodologia do trabalho científico. 23a ed. São Paulo: Cortez; 2005.

SHINVASHIKI, G.T; TREVIZAN, M.A; MENDES, I.A.C. Sobre a criaçáo e a gestáo do conhecimento organizacional. Rev. Latino-Am. Enfermagem. 2003; 11 (4): 499-506.

SILVA, L.D; PEREIRA, S.R.M; MESQUITA, A.M.F. Procedimentos de enfermagem: semiotécnica para o cuidado. Rio de Janeiro: Guanabara Koogan, 2004.

TEIXEIRA E; VALE, E.G; FERNANDES, J.D; SORDI, M.R.L.: org. $\mathbf{O}$ ensino de graduaçáo na enfermagem no Brasil: o ontem, o hoje e o amanhá. Brasília: Instituto $\mathrm{Na}$ cional de Estudos e Pesquisas Educacionais Anísio Teixeira, 2006.
Endereço para Correspondência:

Denise Celeste Godoy de Andrade Rodrigues denise.cgar@gmail.com

Centro Universitário de Volta Redonda Campus Três Poços Av. Paulo Erlei Alves Abrantes, no 1325 , Três Poços - Volta Redonda / RJ CEP: 27240-560 


\section{Anexo A}

TERMO DE CONSENTIMENTO LIVRE E ESCLARECIDO (TCLE)

Comitê de Ética em Pesquisa em Seres Humanos - CoEPS/UniFOA

(Observação: O TCLE deve ser impresso em duas cópias, ficando uma delas sob responsabilidade do Pesquisador Coordenador e a outra sob a guarda do participante)

\section{IDENTIFICAÇÃO DO RESPONSÁVEL PELA EXECUÇÃO DA PESQUISA:}

Título do Projeto: Controle de Infecção Hospitalar: Conhecimento Adquirido na Graduação de Enfermagem

Coordenador do Projeto: Clarice Mayremi Toshimitu Hoyashi

Telefones de contato do Coordenador do Projeto: 9953-7833 / 3347-5899

Endereço do Comitê de Ética em Pesquisa: Av. Paulo Erlei Alves Abrantes, no 1325, Três Poços, Volta Redonda.

\section{INFORMAÇÓES AO PARTICIPANTE OU RESPONSÁVEL:}

(a) Você está sendo convidado a participar de uma pesquisa que tem como objetivo: descrever o entendimento de acadêmicos de enfermagem acerca do conhecimento adquirido sobre a atuação do enfermeiro no controle de infecção hospitalar e Apontar estratégias de atuação de acadêmicos de enfermagem no controle de infecção hospitalar.

(b) Antes de aceitar participar da pesquisa, leia atentamente as explicaçóes abaixo que informam sobre o procedimento. Estamos desenvolvendo esta pesquisa sobre o Controle de Infecção Hospitalar: Conhecimento adquirido na Graduação de Enfermagem. Já que consiste como requisito para conclusão da Graduação em Enfermagem do Centro Universitário de Volta Redonda. Gostaríamos que a V.Sa respondesse um questionário.

(c) Você poderá recusar a participar da pesquisa e poderá abandonar o procedimento em qualquer momento, sem nenhuma penalização ou prejuízo. Durante o procedimento preenchimento do questionário, você poderá recusar a responder qualquer pergunta que por ventura lhe causar algum constrangimento.

(d) A sua participação como voluntário, não auferirá nenhum privilégio, seja ele de caráter financeiro ou de qualquer natureza, podendo se retirar do projeto em qualquer momento sem prejuízo a V.Sa.

(e) A sua participação não envolve nenhum risco.

(f) Serão garantidos o sigilo e privacidade, sendo reservado ao participante o direito de omissão de sua identificação ou de dados que possam comprometê-lo.

(g) Na apresentaçáo dos resultados não serão citados os nomes dos participantes.

(h) Confirmo ter conhecimento do conteúdo deste termo. A minha assinatura abaixo indica que concordo em participar desta pesquisa e por isso dou meu consentimento.

Volta Redonda, de de 20 